\title{
The price of cold ${ }^{*}$
}

NICOLA TWILLEY EDITORA DEL BLOG EDIBLE GEOGRAPHY Y COLABORADORA DE LA REVISTA THE NEW YORKER.

KEYWORDS: FOOD,

REFRIGERATION, CHINA, RESOURCES, CLIMATE

CHANGE
Based on a multidisciplinary research about food's ecological footprint, this article shows that the exponential increase in refrigeration in recent decades has had several harmful effects on the environment: more energy is consumed and more gases that are harmful to the atmosphere are emitted. And, as if that weren't enough, it also increases the production of waste, because since we have refrigerators we buy more food than we are capable of consuming.

«In Sichuan, we're eaters,» said Chen Zemin, the world's first and only frozen-dumpling billionaire. «We have an expression that goes, 'Even if you have a very poor life, you still have your teeth to please.'»

Chen, who is 72 , never planned on being a dumpling mogul. Like almost everyone who came of age during the Cultural Revolution, he didn't get to choose his profession. He was a «gadget guy» during his high school years. «I liked building circuits and crystal radios and that sort of thing,» he told me. «I applied to university to study semiconductor electronics.» But the state decided that Chen should become a surgeon, and so he dutifully completed his studies and amused himself in his free time by learning how to cook: He made Sichuan pickles, kung pao chicken and, of course, dumplings. Even after he became vice president of the Second People's Hospital in Zhengzhou, a provincial city about halfway between Shanghai and Beijing, Chen remained bored with his day job. He engaged in lots of Rube Goldberg-like tinkering: fixing his neighbors' radios, building Zhengzhou's first washing machine. And he cooked. For decades, his Lunar New Year gifts of homemade glutinous rice balls were legendary among friends and neighbors.

But as China began to open up to the West and Deng Xiaoping, Mao's reformist successor, declared that some people «will get rich first,» Chen, who had two sons' weddings to pay for, wanted to become one of those people. Chinese pot stickers and rice balls are traditionally made 


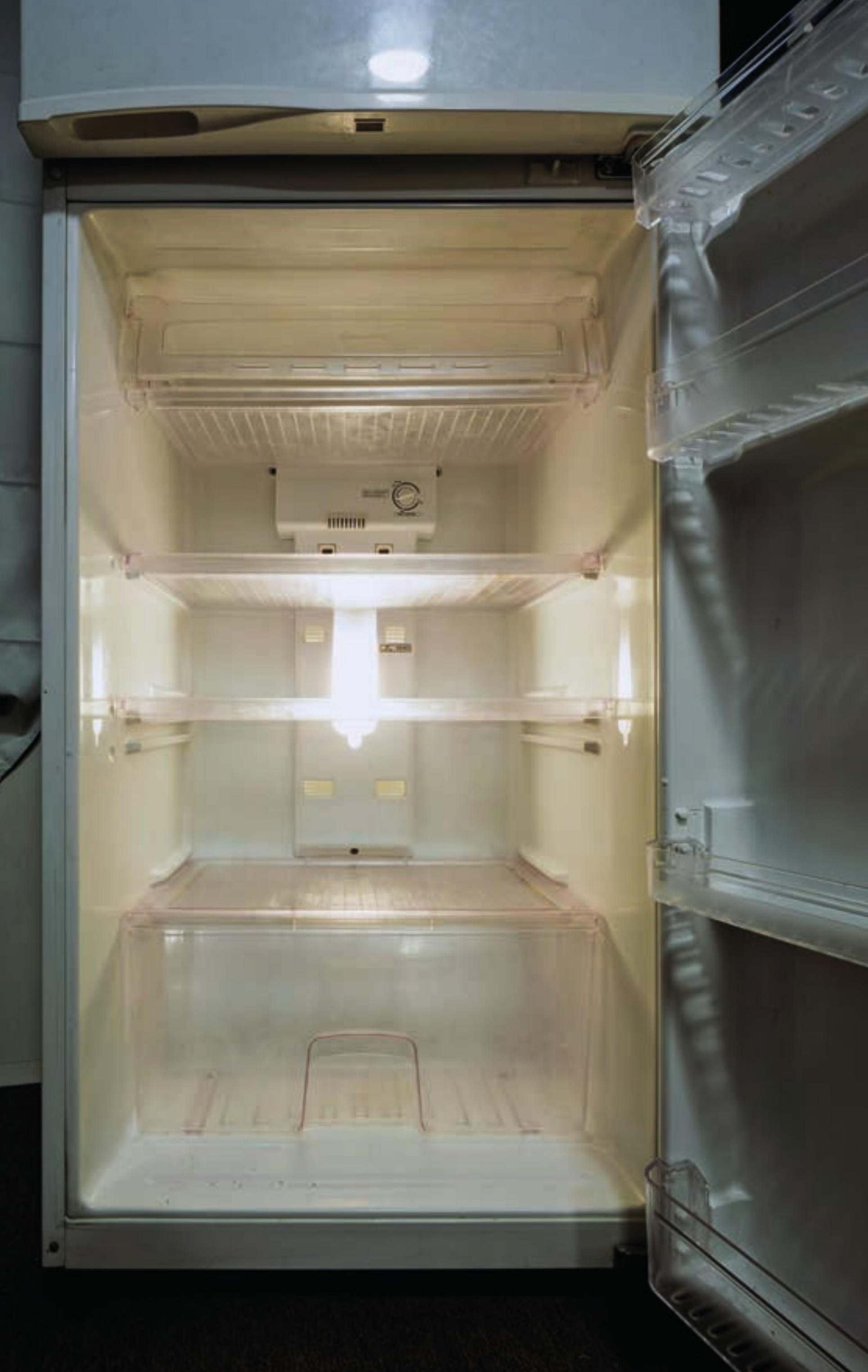


in enormous batches, in order to justify the effort it takes to knead the dough, mix the filling and wrap by hand a morsel that stays fresh for only one day. Thanks to his medical background, Chen had an idea for how to extend the life span of his spicy-pork wontons and sweet-sesame-paste-filled balls. «As a surgeon, you have to preserve things like organs or blood in a cold environment,» Chen said. «A surgeon's career cannot be separate from refrigeration. I already knew that cold was the best physical way to preserve.»

Using mechanical parts harvested from the hospital junk pile, Chen built a two-stage freezer that chilled his rice balls one by one, quickly enough that large ice crystals didn't form inside the filling. His first patent covered a production process for the balls themselves; a second was for the packaging that would protect them from freezer burn. Soon enough, Chen realized that both innovations could be applied to pot stickers, too. And so in 1992, Chen, then 5o, quit his hospital job and started China's first frozenfood business. He named his fledgling dumpling company Sanquan, which is short for the «Third Plenary Session of the 11th Central Committee of the Communist Party of China» - the 1978 gathering that marked the country's first steps toward the open market.

Today, Sanquan has seven factories nationwide. The largest, in which Chen and I were chatting, employs 5, ooo workers and produces 400 tons of dumplings a day. $\mathrm{He}$ showed me the factory floor from a glass-walled skywalk; below us, dozens of workers - in hooded white jumpsuits and white face masks - tended to nearly 100 dumpling machines lined up in rows inside a vast, white-tiled refrigerator.

When Chen founded Sanquan, fewer than one in 10 of his fellow citizens even owned a refrigerator. In the 12 years between 1995 and 2007, China's domestic refrigeratorownership numbers jumped to $95 \%$ from just $7 \%$ of urban families.

An artificial winter has begun to stretch across the country. China had 250 million cubic feet of refrigerated storage capacity in 2007; by 2017, the country is on track to have 20 times that. At 5 billion cubic feet, China will surpass even the United States, which has led the world in cold storage since artificial refrigeration was invented.

This refrigeration boom is not simply transforming how Chinese people grow, distribute and consume food. It also stands to become a formidable new factor in climate change; cooling is already responsible for 15 percent of all electricity consumption worldwide, and leaks of chemical refrigerants are a major source of greenhouse-gas pollution. Of all the shifts in lifestyle that threaten the planet right now, perhaps none is as important as the changing way that Chinese people eat.

In the United States, the first mechanically cooled warehouses opened in Boston in 1881. America's Chen Zemin was a Brooklyn-born entrepreneur named Clarence Birdseye, who invented a fast-freezing machine in 1924 to replicate the taste of the frozen fish he enjoyed while traveling in Labrador. By the 1950s, pretty much everyone in America had a refrigerator.

The Chinese didn't build their first refrigerated warehouse until 1955. And even as skyscrapers and high-speed trains have transformed life in China, the refrigerator represents a significant step forward. Every Chinese person over age 30 whom I spoke to could remember the moment he got his first home refrigerator, with the exception of those who still don't 
have one. Liu Peijun, a 49-year-old logistics entrepreneur who now owns and operates three refrigerated warehouses on the outskirts of Beijing, told me that one of his earliest memories from childhood was of hanging meat outside the window to keep it cold until the Lunar New Year feast.

FOR ALL THE MICROBIAL GROWTH AND FOOD

WASTE THAT REFRIGERATION MIGHT FORESTALL, THE UNCOMFORTABLE FACT IS THAT A FULLY DEVELOPED COLD CHAIN (FIELD PRECOOLING STATIONS, SLAUGHTERHOUSES, DISTRIBUTION CENTERS, TRUCKS, GROCERY STORES AND DOMESTIC REFRIGERATORS) REQUIRES A LOT OF ENERGY.

By the late 1980s, Kentucky Fried Chicken opened its first restaurant in China and began expanding across the country by building its own freezer infrastructure and trucking lines. Wal-Mart jumped into the budding Chinese supermarket scene in 1996 with its own Americanstyle chill cases and refrigerated distribution centers. Leading up to the 2008 Olympics, the Beijing municipal authorities embarked on an ambitious program of «supermarketization,» designed to get meat and vegetables out of the open-air «wet» markets - where food is cooled by standing fans and the occasional hose down from the cold tap - and safely behind sneeze-guards in climate-controlled grocery stores. Around this time, the management consulting firm A.T. Kearney produced a report that both predicted and kick-started the country's refrigeration boom. It projected that mass refrigeration would provide an added value worth $\$ 160$ billion per year by 2017 .

Tax breaks, subsidies and preferential access to land has been made available to anyone aspiring to build a refrigerated warehouse. In 2010, the government's National Development and Reform Commission made expanding the country's refrigerated and frozen capacity one of the central priorities in its 12th Five-Year National Plan.

Driven by this powerful combination of urbanization, rising gross domestic product and government support, demand for refrigeration services has increased by more than 30\% year-on-year in China's major coastal cities.

Despite the expansion in frozen foods and refrigerators, the critical growth area is what's known in the logistics business as the «cold chain»-the seamless network of temperature-controlled space through which perishable food is supposed to travel on its way from farm to refrigerator. In the United States, at least $70 \%$ of all the food people eat each year passes through a cold chain. By contrast, in China, less than a quarter of the country's meat supply is slaughtered, transported, stored or sold under refrigeration. The equivalent number for fruit and vegetables is just $5 \%$.

These statistics translate into scenes that would concern most American food-safety inspectors. In Shanghai, for example, one large pork processor has no refrigeration system; instead, it does all its slaughtering at night, when the temperature is slightly cooler, in a massive shed 
with open sides to allow for a cross breeze. The freshly disemboweled pigs hang for hours in the smoggy air.

A new generation of logistics entrepreneurs like Peijun is emerging to help forge links in the country's nascent cold chain, and, the government hopes, improve the country's food safety in the process. Peijun started out in 1996 as an agent for frozen-food brands like Sanquan, when it first reached Beijing. «I did tastings and promotions in supermarkets,» he said. «People sort of shunned them in the beginning, but the dumplings caught on really fast. I quickly realized that the real bottleneck was not consumer demand but the lack of refrigerated storage and distribution.» Eventually, Peijun decided to start his own company, Express Channel Food Logistics.

Businesses like Peijun's mostly serve China's rising middle and upper classes. But as more entrepreneurs enter the refrigerated-logistics market, the Chinese government is hoping not just to promote food safety but also to prevent an enormous amount of food waste. In its Development Plan for Cold-Chain Logistics of Agricultural Products, China set itself the five-year goal of reducing the loss rate for vegetables, meat and aquatic products to less than $15 \%$, $8 \%$ and $10 \%$ by 2015 . If the nation hits those targets, the effort could save a large part of the more than $\$ 32$ billion in food now wasted, but at this point, there is quite a way to go. Nearly half of everything that is grown in China rots before it even reaches the retail market.

For all the microbial growth and food waste that refrigeration might forestall, the uncomfortable fact is that a fully developed cold chain (field precooling stations, slaughterhouses, distribution centers, trucks, grocery stores and domestic refrigerators) requires a lot of energy.

Clyde Verhoff, vice president of engineering for Emerson's Asia division, claims that he can predict the hum that a new refrigeration component will make before it is even built. Last summer, Emerson helped the Spanish supermarket chain Dia consume 25 percent less electricity in their Shanghai stores by designing an energy efficient, automated control system. But as we sat at a conference table there was an awkward pause when I asked Mark Bills, who helps lead Emerson's refrigeration business in Asia, about the environmental consequences of China's building the same amount of cold space per person as the United States. «If you assume that there's going to be doubledigit growth in the cold chain for the foreseeable future,» Bills began, hesitantly. He paused, searching for the right phrase. «Well, to think that there's going to be double-digit efficiency savings for the foreseeable future, year over year, is» - he paused - «a challenge. We're doing what we can to help influence that in a positive light, but at the end of the day, there's going to be...» Bills let his sentence trail off, throwing open his hands and shrugging in the universal gesture for «we're in trouble.» Verhoff stepped in. «We're really hitting the limit of what can be done,» he said.

Calculating the climate change impact of an expanded Chinese cold chain is extremely complicated. Artificial refrigeration contributes to global greenhouse gas emissions in two main ways. First, generating the power that fuels the heat-exchange process, which is at the heart of any cooling system, accounts for about $80 \%$ of refrigeration's global-warming impact (measured in tons of carbon dioxide) and currently consumes nearly a sixth of global electricity usage. 
But the other problem is the refrigerants themselves: the chemicals that are evaporated and condensed by the compressors in order to remove heat and thus produce cold. Some of that refrigerant leaks into the atmosphere as a gas. Different refrigeration systems use different refrigerants, some of which, like ammonia, have a negligible globalwarming impact. But others, like the hydrofluorocarbons that are popular in China, are known as «supergreenhouse gases,» because they are thousands of times more warming than $\mathrm{CO}_{2}$.

"FOOD WASTE IS A JUSTIFICATION FOR REFRIGERATION," FREIDBERG SAID. "BUT AT THE SAME TIME, THERE ARE STUDIES THAT SHOW THAT, OVER THE LONGER TIME FRAME, THE COLD CHAIN ENCOURAGES CONSUMERS TO BUY MORE THAN THEY'RE GOING TO EAT."

To make matters worse, it's not even clear that refrigeration reduces food waste over the long term. Logically, it would seem that a refrigerator should result in less food waste at home, slowing down the rate at which vegetables rot and milk sours. But Susanne Freidberg, a geography professor at Dartmouth College and author of Fresh: A Perishable History, says that refrigeration in the United States has tended to merely change when the waste occurs. Americans, too, throw away $40 \%$ of their food, but nearly half of that waste occurs at the consumer level, meaning in retail locations and at home. «Food waste is a justification for refrigeration,» Freidberg said. «But at the same time, there are studies that show that, over the longer time frame, the cold chain encourages consumers to buy more than they're going to eat.»

The impact of refrigeration goes beyond warming the planet and (perhaps) reducing food waste. By artificially extending the life span of otherwise perishable fruits, vegetables and animal products, refrigeration changes almost everything about how we know and interact with food.

Fuchsia Dunlop, a British cook and author who writes about Chinese cuisine, described how she saw traditional food-preservation skills die out over the past two decades, as refrigeration gained ground. «When I first lived in China, in 1994,» she said, «everything was dried, pickled or salted. On sunny days, people would be laying all kinds of vegetables out to dry in the sun, and some of them afterward would be rubbed with salt and put in jars to ferment. Other vegetables would be pickled in brine and preserved neat. In Chengdu, they would hang sausages and pork under the eaves of the old houses to dry, and there were these great clay pickle jars in people's homes.»

Now, though, most of those old houses have been demolished. At the moment that America's long-lost pickling and salting traditions are being revived, China's more ancient preservation techniques are dying out.

Not all Chinese people are ready to embrace the refrigeration revolution. Dai Jianjun is the 45 -year-old chef of Longjing Caotang, a restaurant on the outskirts of Hangzhou, the capital of Zhejiang province, which serves an entirely locally sourced cuisine. When I asked him how he 
liked frozen dumplings, he took off his corduroy cap, rubbed his shaved head with both hands and said, «If I may speak without reserve, they're not food.»

Over the course of two epic meals, separated only by a paddle on a local lake to catch fish for dinner, Dai fed me dried vegetables, vinegar-pickled radishes, fermented «stinky» tofu and peanuts that six months earlier had been packed into earthenware jars. After our boat ride, the fish boss, who went by the name Mr. Wang, prepared a delicious yellow-mud-preserved duck egg, which, he told me, keeps at room temperature for 30 days.

The rest of the ingredients were harvested or foraged that day. Not a single thing I was served had been refrigerated.

The food was revelatory: complex but light and offering a more subtle yet diverse range of flavors than I had previously encountered in Chinese cuisine. Dai himself barely ate, preferring to smoke and drink (first green tea, then baijiu, a spirit distilled locally from glutinous rice).

Toward the end of the evening, I mentioned that, in 2012, Britain's Royal Society had named refrigeration as the most important invention in the history of food and drink. With their faces already reddened from the liberal consumption of baijiu, Dai and the other men all convulsed with laughter. Once he had composed himself, Dai said, «Within our circle, you sound ridiculous!». ARQ

(C) 2014 The New York Times From The New York Times Magazine Distributed by The New York Times Syndicate

BIBLIOGRAFÍA / BIBLIOGRAPHY

FREIDBERG, Susanne. Fresh: A Perishable History (Cambridge, MA: Belknap Press, 2010)

NICOLA TWILLEY

BA (First Class) in English Literature from Leeds University, and a MA in Art History from the University of Chicago. She is author of the blog Edible Geography, co-host of the Gastropod podcast, and a contributing writer at The New Yorker. She has developed research on food's ecological footprint and refrigeration, and is currently writing a book on the topic. 


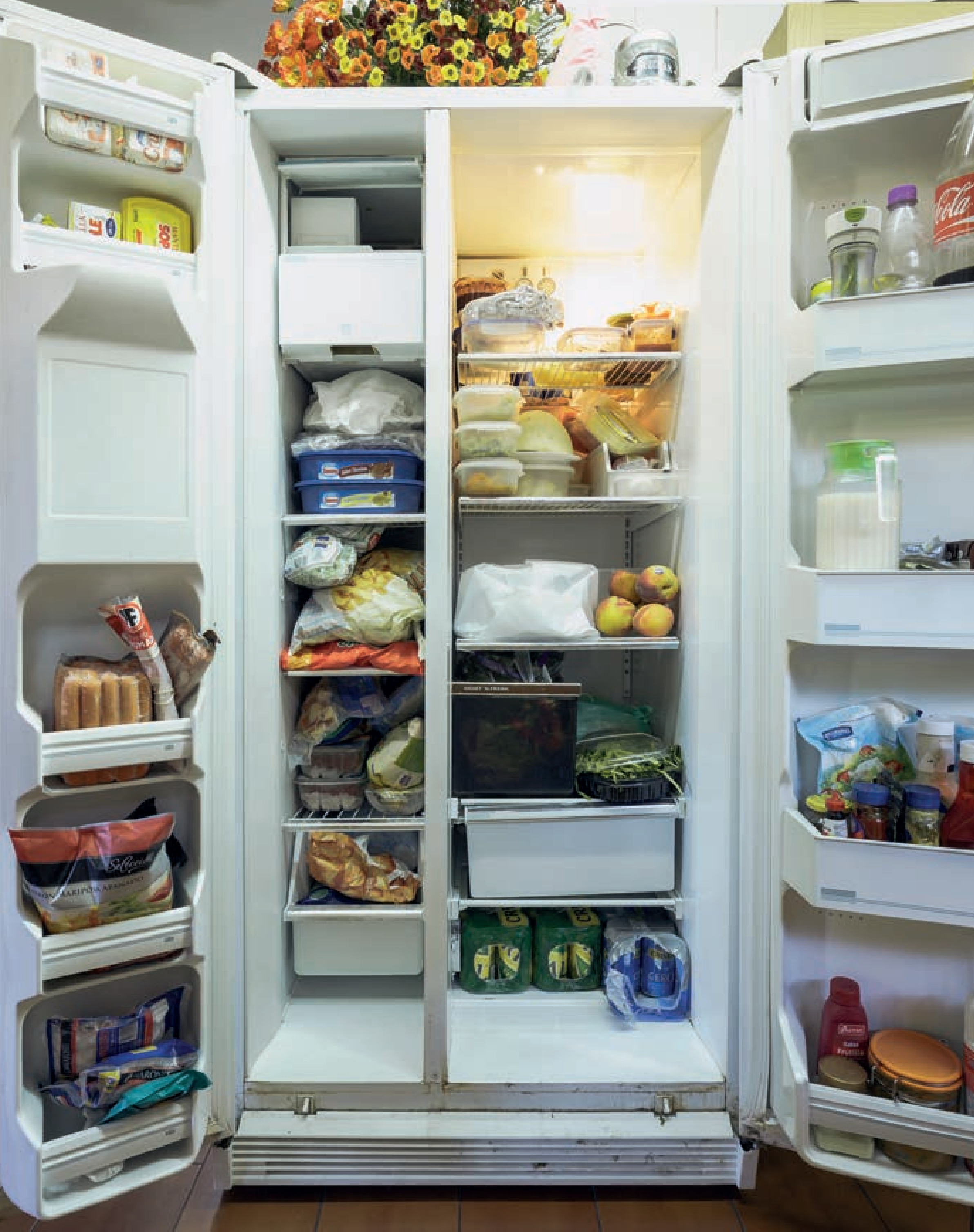

